Peer-Reviewed Article

ISSN: 2162-3104 Print/ ISSN: 2166-3750 Online

Volume 7, Issue 3 (2017), pp. 433-448

(C) Journal of International Students

http://jistudents.org/

doi:10.5281/zenodo.570022

\title{
Confucianism and Accents: Understanding the Plight of the Asian International Student in the U.S.
}

\author{
Jennifer T. Young \\ California State University, Long Beach, USA
}

\begin{abstract}
Research has shown that international students experience acculturation stress while adjusting to life in the U.S., resolving over time. However, acculturation stress can be exacerbated by several factors, leading to a negative impact on academic performance and general wellness. Asian international students traditionally underutilize counseling services on campuses. This article reviews literature of the experiences of Asian international students studying in the U.S. The author offers Confucianism as a cultural consideration to explain cross-cultural challenges experienced by Asian international students and their campus community. Suggestions to support Asian international students are made based on findings of the literature review.
\end{abstract}

Keywords: Asian international students, Confucianism, English language, mental health

International students currently constitute $4.8 \%$ of the U.S. higher education population, representing a record high and a $10 \%$ increase within the past year (Institute of International Education, 2015). Over the past decade, the number of international students studying in the U.S. increased from 572,509 in $2003 / 4$ to 974,926 in $2014 / 15$. In $2014 / 15$, the majority of international students in the U.S. are arriving from Asian nations such as China (31.2\%), India (13.6\%), South Korea (6.5\%), Japan (2\%), Taiwan (2.2\%), and Vietnam (1.9\%), totaling 57.4\%. Recruiting students internationally is highly lucrative for U.S. universities (Andrade, 2009). International students contributed nearly $\$ 30.8$ billion to the U.S. economy in 2014/15 (Institute of International Education, 2015). Furthermore, international students also offer global perspectives and cultural diversity to U.S. campuses. 
Given the economic and educational advantages of international student presence in higher education institutions, the number of international students studying in the U.S. will likely continue to increase. As such, higher education institutions in the U.S. are focusing on providing programs and services that adequately support the international student community. One example of student support services is mental health counseling. Recent research of international students show that although this population underutilizes campus counseling services, those who use services are Asian international students (Hwang, Bennett, \& Beauchemin, 2014).

With the majority of students arriving to the U.S. from Asia, it is no surprise that literature examining the international student experience in U.S. higher education institutions largely deals with students from Asia (Andrade, 2006; Trice, 2007). Many international students do not have abnormal difficulty with adjustment, however those who struggle vary greatly in their ability to cope. Among those who have difficulties, the challenges faced by Asian international students are well documented with particular attention to mental health concerns (Chen \& Lewis, 2011; Constantine, Okazaki, \& Utsey, 2004; Dao, Lee, \& Chang, 2007; Lee, Koeske, \& Sales, 2004). The volume of research on Asian international students in the U.S. and mental health concerns intimate the possibility that fundamental cross-cultural underpinnings are present and may require exploration to further understand cultural differences (Dao, 2007; EllisBosold, 2013). Yet, there is a lack of literature available that offers a deeper understanding of the adjustment experience for Asian international students.

This article endeavors to provide an understanding of Asian international students' experiences studying in the U.S. by looking at Confucian values. Much of the literature examining Asian international student experiences consist of students coming from cultures with deeply rooted Confucian values (e.g. Japan, South Korea, China). According to Taylor (2011), South Asian and East Asian cultures have roots in Confucianism. There is sufficient research examining South and East Asian international students, explainable by the large percentage of these groups represented among international students studying in the U.S (Institute of International Education, 2015). Considering that many Asian international students are arriving from cultures notably rooted in Confucianism, three key Confucian tenets will be presented to provide a deeper understanding of Asian international student experiences.

\section{LITERATURE REVIEW}

The literature was selected by searching for key terms "international student”, “college”, “counseling” and "mental health” within counseling and clinical psychology journals and higher education journals. The search was originally conducted in 2012 using several databases such as Academic 
Search Premier, Education Research Complete, Psych Articles, and Psych Info. During 2012, the author was examining international student concerns to assist in the development of a support group at a university counseling center. During the editing process for the manuscript, a new search was also conducted in 2015 and new research was included.

\section{Mental Health and Wellbeing of Asian International Students}

The literature review on mental health and international students suggest that, although a large number of international students adjust successfully (Misra \& Castillo, 2004), many international students endure challenges related to adjustment in a new academic culture (Mori, 2000), culture shock, coping with long distance relationships, feelings of loneliness and homesickness, and stress of language fluency (Andrade, 2006; Chalungsooth \& Schneller, 2011). Studies examining data of international students who utilize campus counseling centers show anxiety, depression, adjustment and learning issues as common complaints (Hwang, Bennet, Beauchemin, 2014; Poyrazli, 2015). Still, many international students do not use mental health services or are unaware of services available.

International students who engage in mental health services are reported to also be more likely to terminate treatment, endorse suicide ideation, use crisis services, and be hospitalized compared with domestic students (Mitchell, Greenwood, \& Guglielmi, 2007). Another study suggested that international students with poor adjustment and low support during the first six months to twelve months of arriving in the U.S. are more susceptible to mental health crises (Mitchell et al., 2007). At the time that this article was written, virtually no research was found examining possible causes for higher utilization rates of crisis and hospitalization services among international students. Nonetheless, susceptibility to crisis can be attributed to stigma surrounding help-seeking and mental health in general (Chen \& Lewis, 2011; Masuda et al., 2009), which deters students from seeking support until they are in distress. Newly arrived international students lack domestic support and are geographically far from loved ones. This leaves many international students in a vulnerable position. Without proper support, adjustment challenges can progress into more urgent mental health problems. Reluctance for Asian international students to seek external support suggests that there are cultural implications to be explored. The following is an overview focusing on a few tenets of Confucianism that endeavors to provide alternative considerations to challenges of Asian international students brought forth by existing research and literature.

\section{Confucian Values}

The review of Confucianism values was principally referenced from the book Confucianism: The Analects, by Robert Taylor. According to 
Taylor (2011), Confucius is the Latinized name for the Chinese scholar K'ung Ch'iu, who sought to develop moral teachings focused on living a life filled with goodness. K'ung Ch'iu, later known as Master Kung, strived to achieve societal peace and harmony during a time of socio-political and religious chaos amidst the disintegration of the Chou dynasty. Master Kung (Confucius) believed that self and society were not separate. Thus, to achieve goodness as a whole in this system, individuals needed to manifest goodness in one's self. Achieving goodness in oneself requires a commitment to two central tenets: moral development and social harmony. Confucianism offers an array of teachings, however; a few select virtues are highlighted for the purpose of the article: 1) "rén” 仁, human-heartedness, benevolence; 2) “li” 禮, politeness, correct behaviors, rites; and 3) “xiào” 孝 , filial piety. "Xiào" can be classified as a subset of "rén."

Within these virtues lie the essence of many Asian values (Taylor, 2011). For example, attaining "rén" requires that one enters self-study in order to cultivate humane action while striving for moral goodness. "Xiào", the demonstration of filial piety, is one method to achieve "rén". "Xiào" describes mutual love and respect between parent(s) and child(ren) and explains that the obligation between the two parties is demonstrated by responsible action. That is, parents are responsible for providing their children with proper education, nurturing, and a solid moral foundation. In return, children are responsible for showing their respect and appreciation through obedience and service to parents (Taylor, 2011). In this belief system, filial piety shows that one can move beyond self-centeredness and ego thereby showing benevolent action, or "rén." Those who are from cultures influenced by Confucian values often show respect to parents, elders, and persons in authority by showing obedience. This is shown by refraining from questioning authority and agreeing to commitments due to a sense of duty and respect for their elders.

"Li" is a virtue which describes politeness and correct action. This is evident in the form of cultural rituals, such as burning paper money while honoring ancestors, or behaving in a caregiving manner such as serving your elders before serving yourself during a meal. Conducting oneself in a correct manner is also related to "face saving". Face saving, or "saving face", is to behave in a way that avoids bringing shame or embarrassment upon oneself and others. It is not simply about being polite toward others but also about anticipating the thoughts, feelings, actions of others and acting in accordance to minimize potential discomfort for all, maintaining group harmony. For example, international students may often forgo their own needs to save face or not inconvenience others. These virtues will be used to provide a perspective of Asian international students' experiences.

The review of literature on Asian international students studying in the U.S revealed five recurring themes: (a) insecurity with English 
Language proficiency, (b) real or perceived discrimination, (c) stigma of help-seeking, (d) relations with faculty, and (e) challenges with social support. Additionally, several studies reported that international students had a strong desire to connect with U.S. domestic students and felt their efforts were in vain. The preponderance of research on adjustment concerns and mental health of Asian international students indicate that existing student services for this group need to be reconsidered.

\section{The Plight of Asian International Students}

English Language Insecurity. Degree-seeking international students are required to pass an English proficiency exam prior to enrollment as a matriculating student at a U.S. institution (Mori, 2000). Research suggests most international students who report difficulty with English language are often from Asian countries. Several studies with samples of international students from East Asian and South Asian countries found that depression and mental health symptoms were correlated to English language fluency, among other factors (Andrade, 2009; Dao, Lee, \& Chang, 2007; Fritz, Chin, \& DeMarinis, 2008; Lee, Koeske, \& Sales, 2004; Meifen et al., 2007; Rahman \& Rollock, 2004; Yakunina, Weigold, \& McCarthy, 2011). It was also found that English language proficiency served as a precipitator for acculturative stress (Tung, 2011; Yeh \& Inose, 2003) and culture shock (Swagler \& Ellis, 2003), which, when unaddressed, can also lead to anxiety and depression.

English language fluency concerns have been noted in literature studying the immigrant experience. Chan (2013) found that feeling embarrassed about non-fluency followed by perception of critical or negative judgment by fluent speakers can lead to isolation and withdrawal among immigrant children. Within the international student population, those who struggle with English language fluency face a similar experience which contributes to difficulties adjusting socially and academically. International students are often both surprised by and ashamed of their linguistic weakness upon arriving in the U.S., a stark contrast to the competence they felt while in their home country. It can be daunting and embarrassing to believe they have achieved English fluency only to realize that their English needs improvement. Self-consciousness about their language accent can make connecting with others uncomfortable. Feelings of shame, shyness, and embarrassment can eventually lead to social withdrawal, decreased classroom participation, and lower self-esteem. For international students rooted in Confucian cultures, the virtue of "li" suggest that international students are not proactive in seeking guidance in the form of tutoring or from asking questions because doing so is to admit that there is a weakness which may bring a "loss of face". Furthermore to ask others 
for assistance with their limitation can be viewed as burdening others with their problem. Individuals from cultures who do not ascribe to these values may have difficulty understanding the difficulty for Asian international students to seek support.

Discrimination. Research studies have consistently shown that perceived discrimination reported by international students is negatively linked to overall satisfaction with their lives in the U.S. (Ye, 2005). Perceived or real experiences of being discriminated against can strike at one's self-esteem (Schmitt, Spears, \& Branscombe, 2003) and lead to higher levels of anxiety, depression, loneliness and physical health complaints (Jung, Hecht, \& Wadsworth, 2007; Poyrazli, \& Lopez, 2007). Perceiving discrimination can affect a student's sense of belonging, a considerable human need (Maslow, 1962). Individuals who feel their sense of belonging is threatened will often experience existential angst and fear of being ostracized (Maslow, 1962; May, 1983). As such, being rejected or having perceptions of rejection by social groups can induce high anxiety and have negative repercussions on psychological health and wellness.

It is noteworthy to consider that international students from South and East Asian countries are often accustomed to a more homogenized society than that which exists in the U.S. Therefore, diversity, or "otherness", may be experienced more intensely than those from countries with societies comprised of more racial and ethnic diversity. All things considered, these experiences juxtaposed with Confucian values may cause internal conflict or dissonance. To illustrate, the virtue of "rén" teaches individuals to act in way that fosters honor and respect between all people. And "li" enforces paying respect to others. For Asian international students adjusting as a foreigner, locals in the U.S. may be perceived to have more authority. Those students who are self-conscious about their spoken English ability or speaking accented English can experience higher levels of stress on a daily basis.

Research shows that Asian international students consistently report encounters with discrimination (Jung, Hecht, \& Wadsworth, 2007; Poyrazli, \& Lopez, 2007). Notwithstanding, it is also possible that Asian international students who are experiencing acculturative stress can perceive a stranger's non-discriminating, but explicit expression of rudeness as discriminatory due to its unfriendly nature and the fact that the interaction is occurring outside of a familiar context. To verify discrimination, exercising "rén" and "li" would require one to engage in sensitive dialogue and communicate with the offender. This can appear an insurmountable feat for a selfconscious, newly arrived foreigner.

A perception of discrimination by the dominant majority is particularly harmful in that the exclusion sends a message that the person is 
considered abnormal (Schmitt, Spears, \& Branscombe, 2003). Discrimination has been tied to lower academic achievement, discomfort in classroom settings, (Kernahan, Wei, \& Davis, 2014) and can be a factor of attrition among college students (Hurtado \& Carter, 1997). For instance, literature studying the experience of students of color (SOC) indicate that discrimination can have a negative effect on the overall college experience and sense of belonging on campus. The literature suggests higher education institutions in the U.S. have a responsibility to effectively manage diversity within the college student population (Levin, Van Laar, \& Foote, 2006; O’Keeffe, 2013), both domestic and international.

Stigma of Help-Seeking. Although psychology is over a century year old, mental health stigma continues to exist globally. The term stigma refers to negative judgment of a person or group when their behaviors or characteristic are different or inferior from that of the societal norm (Ahmedani, 2011). Different groups will hold stigma about ideology that other groups, or out-groups, will not endorse. Research shows that Asian students who espouse traditional Asian values tend to endorse negative attitudes toward counseling and are less likely to seek mental health support when needed (Yakunina \& Weigold, 2011). Stigma continues to be a deterrent in addressing mental health concerns in China, Japan, and South Korea (Chen \& Lewis, 2011). It is suggested that, since the traditional Asian values of collectivism, humility, conformity, and emotional self-control directly contradicts Western values of individualism, assertiveness, and open expression of emotion, Asian students often have negative attitudes toward counseling (Yakunina \& Weigold, 2011).

Help-seeking, or lack thereof, is another example where the influence of Confucian values is implicated. Confucius emphasized the importance of managing one's hardship without complaining (Taylor, 2011). According to Taylor (2011), emotional strength is emphasized and demonstrated when one is able to control their behaviors despite their feelings. Coupled with a deep sense of filial piety, it is easy to imagine how those from Confucian-based cultures do not view counseling or seeking help as a viable or helpful option. To do so could bring shame and embarrassment on both the international student seeking support, his/her family, and, in the perception of the international student, on those professionals whom they are troubling for help. In an effort to be polite and save face, individuals feel an obligation to resolve the issues themselves.

Additionally, Asian international students may not be agreeable to speaking truthfully with their parents about the challenges they experience in the U.S. as a result of "xiào" and "li". That is, due to their love and respect for their parents (filial piety, "xiào"), they do not want to worry them or bring shame upon themselves or their family for their struggle (politeness 
and saving face, "li"). In a non-Confucian culture, this can be viewed as avoidant behavior, or at the very least, unhelpful behavior. Yet to dismiss this action as such would not only be an enormous misunderstanding, but also an invalidation to international students who are acting properly within their home country's cultural context.

To illustrate, one method of coping popular among Asian international students is frequent internet use. Frequent internet use is considered unhealthy and is correlated with depressive symptoms (Shaffer, Hall, \& Vander Bilt, 2000). Frequent internet use, also termed internet overuse, is viewed as problematic for college students. Excessive webbrowsing or gaming can be viewed as enabling procrastination or socially isolating behaviors. However, Ye (2005) found in his study that international students who reported perceived discrimination were more likely to use the internet for coping and relaxation. According to Ye (2005), the internet can also provide opportunities to increase English language fluency via chatting or language learning applications.

Information found on the internet can also aid one's cultural adjustment without inducing feelings of self-consciousness about English language fluency which is present during social interactions. Used in moderation, the internet can be a safe way for international students to connect socially without risking social rejection or discrimination and can provide a medium to combat loneliness. International students can communicate with loved ones and access information about one's home country cultivating a sense of familiarity, comfort, and belonging in a place where little exists (Ye, 2005). Internet addiction is a legitimate problem for many college students, but frequent internet use can be one method for international students to exercise the Confucian virtue of "li" and attempt to resolve the problem without burdening others.

Relations with Faculty. An acceptable method to seek support is when it is related to academics. However, international students often turn to faculty advisors also when facing an emotional problem (Hyun, Quinn, Madon, \& Lustig, 2007). Faculty support can provide protection from stress and depression among international students. In fact, due to the stigma of mental health and lack of knowledge about counseling services, international students are less likely to reach out to university and college counselors, family members, or even peers and friends when facing a mental health issue. Rather, they are most likely to approach their professors (Trice, 2007).

Most faculty members in the U.S. recognize that international students face unique personal and academic challenges (Trice, 2004). Still many faculty complain of difficulties working with international students. In a study using focus groups, faculty members reported a sense that presentation of class materials needed to be adjusted for international 
students, although not the level of difficulty. These findings suggest that international students may not grasp vital concepts in their courses due to external factors outside of course content, for example, linguistic challenges (Andrade, 2009) or unfamiliarity with presentation methods. Yet, many faculty conclude that international students are struggling as a result of procrastination, lack of participation in the classroom, social segregation, in addition to inadequate English language fluency (Trice, 2007).

According to Trice (2007), such conclusions are based on misconceptions and only a few faculty members have a true grasp of the problem. Trice (2004) conducted a qualitative study interviewing faculty from four departments in a university with a large number of international student enrollment about their perceptions of struggling international students. Results suggested faculty perceptions that international students only want to associate with other international students and are unable to tolerate cultural discomfort (Trice, 2004).

Asian international students in Andrade's study (2006) reported feeling that many U.S. professors were indifferent to teaching Asian international students. Asian international students prefer individual over peer group study, and lacked confidence in their English language ability, which served as a barrier for in-class participation. However, faculty often misinterpreted international students' lack of verbal participation and reluctance for group projects as a lack of taking responsibility for their own learning. Faculty members did not recognize that coming from an entirely different educational pedagogy posed as an academic barrier for international students and also induced mild to moderate psychological distress (Andrade, 2006). Furthermore, faculty members did not appear to consider linguistic insecurity as a possible source of socialization patterns. These findings intimate that the misconceptions of international students by U.S. faculty members that can have a negative impact on the academic performance of these students. Additionally, international students may not be able to identify these barriers, and if they did, due to Confucian values of "li", Asian international students would be hard-pressed to raise an issue with their professor. This is unfortunate given that international students often approach their faculty members first when in need of personal or professional guidance and support.

For Asian international students, adjusting and succeeding in U.S. academic settings where self-expression and expression of critical thinking are highly valued can be confusing and disorienting. For example, in the U.S., a portion of a student's class grade is class participation, which is evaluated by a student's verbal participation in the classroom. Participation is oft demonstrated by asking questions, sharing ideas, challenging their peers appropriately, and offering opinions as well as turning in online discussion assignments. On the contrary, academic settings in East Asian 
countries have not encouraged verbal in-class participation. In fact, asking questions, offering opinions, challenging peers, can be perceived as rude or out-of-line by professors in East Asia, which can have undesirable consequences for students.

In East Asian countries, asking questions of the presenter can be viewed as a message to the presenter that his/her presentation was inadequate and insufficient in explaining concepts. Otherwise, there would be no questions. Additionally, the Confucian value of "xiào", that is, discouragement of questioning those in authority, applies in this circumstance. Challenging others or offering dissenting opinions can be interpreted as self-important or disagreeable, viewed as unharmonious, and causes the presenter to "lose face". These opposing values in U.S. and Asian academic settings create a difficult situation for Asian international students studying in the U.S. Consequently, Asian international students in the U.S. can potentially receive a lower grade for not verbally participating. Yet to do so is unnatural and would require concerted efforts to unlearn certain values upheld in their home culture. Such students would have to retrain their learning styles and compromise their values in order to operate according to academic rules in the U.S.

Social Support. Inadequate social support among Asian international students was also found in the review of literature. Confucian virtues were not used to explain the challenges that Asian international students experience when forming new friendships. However, given that these challenges emerged in the literature review and is essential in understanding the Asian international student context, it will be discussed.

International students are often criticized for banding together and forming ethnic enclaves, and are perceived as having no interest in integrating with their domestic peers. Literature examining the experience of students of color (SOC) also report similar findings (tir, Van Laar, \& Foote, 2006; O’Keeffe, 2013). Ethnically similar peers gravitate toward one another on campus and appreciate the ease of connecting with peers in their in-group. This is especially true when SOC feel a lack of sense of belonging either due to perceived discrimination or other racial stereotypes embodied by members of the campus community. Similarly, international students who engage in ethnic clustering and segregation are often misunderstood. Ethnic clustering is mistakenly viewed as a lack of desire to integrate and participate in the larger campus community, rather than viewed as a natural result of individuals seeking belonging and sense of community.

In fact, contrary to the belief that exclusivity is preferred, several studies report that international students actually have a strong desire to form relationships with domestic students (Hechanova-Alampay, Beehr, Christiansen, \& Van Horn, 2002; Munley, Thiagarajan, Carney, Preacco, \& 
Lidderdale 2007; Rajapaksa \& Dundes, 2003) but found developing these relationships presents an onerous hurdle. International students with weak social support generally report higher levels of mental health symptoms (Lee, Koeske, \& Sales, 2004), such as depression (Ying, \& Han, 2006) and anxiety (Rajapaksa \& Dundes, 2003; Sümer, Poyrazli, \& Grahame, 2008), feelings of hopelessness, loneliness, and higher acculturative stress (Smith \& Khawaja, 2011).

In their literature review, Smith and Khawaja (2011) found that over $50 \%$ of Asian international students studying in the U.S. reported difficulties befriending domestic students but wanted them. Smith and Khawaja (2011) suggested the difficulty for Asian students to establish relationships with domestic students is possibly reflective of "conflicting acculturation attitudes between host universities and international students” (p. 704). Furthermore, international students fortunate enough to have successful relationships with domestic students report lower levels of homesickness (Ying, 2002) and acculturative stress (Poyrazli, Kavanaugh, Baker, \& AlTimimi, 2004). It appears that the desire among international students to connect with domestic students is present but unexamined barriers exist preventing the formation of these relationships. This is peculiar given the mutual benefit of domestic-international relationships. Domestic students can help facilitate healthy acculturation with international students and international students can increase the cultural awareness and enhance global perspectives among domestic students. The literature suggests that higher education institutions can support their students by providing more opportunities for domestic-international, cross-cultural interactions.

\section{Suggestions to Support Asian International Students}

The literature reviewed in this article suggests that Asian international students majorly seek support from faculty even when problems discussed have emotional content. Aside from faculty, international education offices on campus usually focus on administrative tasks and university counseling centers focus on mental health concerns. Some literature suggests that those who are particularly influenced by the traditions of their ethnic culture may be more reluctant to engage support systems on campus at all (Chen \& Lewis, 2011). This supports the suggestion that those influenced by Confucian values are reluctant to seek external support for fear of losing face. The concern of losing face by seeking support can eventually lead to detrimental effects on the emotional wellbeing among Asian international students. Lack of social support and failed attempts to resolve challenges on their own can lead these students to use crisis services as an intervention, leaving other support avenues untapped. 
The author suggests that university student services provide support for Asian international students by providing dual-focus programming to (a) decrease English language insecurity and (b) addressing cross-cultural concerns. Programs are advised to help increase awareness among Asian international students' of their existing cultural values in a validating manner while exploring possible challenges to adjusting to a non-Confucian culture. These programs can support Asian international students by addressing academic performance difficulties which may stem from English language insecurity. Furthermore, it is also suggested that programming include leadership by domestic peer/mentors and faculty/staff liaisons who can normalize adjustment challenges and provide informal support. Informal support may be better received by students arriving from cultures that endorse stigma of help-seeking. Having the support of domestic campus members cultivates a validating environment for international students who may otherwise withdraw when faced with adjustment and emotional challenges. Such programs can increase connections between international and domestic members of campus communities.

The author echoes recommendations of other researchers regarding the importance of educating and training staff and faculty on ways to work sensitively with international students (Tung, 2011). Understanding the multiple contexts of Asian international students can explain behaviors and deter misperceptions hindering academic and social success for Asian international students. Universities and colleges in the U.S. have developed numerous ally programs. Examples include ally training for veteran service members (e.g. VetNet), students identifying as LGBTQ (e.g. Safezone), different-abled students, and students with mental illness (e.g. Mental Health First Aid). Given the growing number of Asian international students entering U.S. higher education institutions, universities are encouraged to provide training to faculty, staff, and administrators to increase awareness and understanding international student populations.

\section{CONCLUSIONS}

This article provided a few examples of the conflicts that arise when Asian international students from cultures rooted in Confucian values study and live in the U.S., a non-Confucian culture. It is vital to avoid misperceptions of international students from Confucian cultures as procrastinating, uninterested, intentionally socially segregated and isolated, or lacking in critical thinking skills. Instead, educators and administrators at higher education institutions can be helpful if a more complete picture of the cultural contexts is explored when considering the behaviors and experience of Asian international students. More specifically, international students may feel embarrassed of the challenges they face and believe that the only resolution lies in their individual ability to stay strong and persevere. Thus, 
the absence of engaging support services is not necessarily an act of noncompliance or resistance, but of differing cultural values. In considering programs and services, it is recommended that the cultural training in the form of ally programs are used to address cultural variance which can serve to prevent unintended alienation, marginalization, or cultivation of further stereotypes or misperceptions of Asian international students. For higher education institutions to meet their goals of providing an educational experience to prepare students to function in an increasingly global context, it is imperative that educators and administrators reflect on their own views and see their students with cultural clarity.

\section{REFERENCES}

Ahmedani, B. K. (2011). Mental health stigma: Society, individuals, and the profession. Journal of Social Work Values and Ethics, 8(2), 1-14.

Andrade, M. S. (2006). International students in English-speaking universities: Adjustment factors. Journal of Research in International Education, 5(2), 131-154.

Andrade, M. S. (2009). The effects of English language proficiency on adjustment to university life. International Multilingual Research Journal, 3(1), 16-34. doi: 10.1080/19313150802668249

Chalungsooth, P., \& Schneller, G. R. (2011). Development of translation materials to assess international students' mental health concerns. Journal of Multicultural Counseling and Development, 39(3), 180-191.

Chan, E. (2013). A narrative research study - Living in the space between participant and researcher as a narrative inquirer: Examining ethnic identity of Chinese Canadian students as conflicting stories to live by. In J. W. Creswell (Ed.), Qualitative inquiry and research design: Choosing among five approaches (3rd ed., pp. 303-326). Los Angeles: Sage Publications.

Chen, H. M. \& Lewis, D. (2011). Approaching the 'resistant:' Exploring East Asian international students' perceptions of herapy and help-seeking behavior before and after they arrived in the United States. Contemporary Family Therapy: An International Journal, 33(3), 310-323. doi: 10.1007/s10591011-9154-6

Constantine, M. G., \& Okazaki, S., Utsey, S. O. (2004). Self-concealment, social self-efficacy, acculturative stress, and depression in African, Asian, and Latin American international college students. American Journal of Orthopsychiatry, 74(3), 230-241. doi: 10.1037/0002-9432.74.3.230

Dao, T. K., Lee, D., \& Chang, H. L. (2007). Acculturation level, perceived English fluency, perceived social support level, and depression among taiwanese international students. College Student Journal, 41(2), 287-295.

Fritz, M. V., Chin, D., \& DeMarinis, V. (2008). Stressors, anxiety, acculturation and adjustment among international and North American students. International Journal of Intercultural Relations, 32(3), 244-259.

Hechanova-Alampay, R., Beehr, T. A., Christiansen, N. D, \& Van Horn, R. K. (2002). Adjustment and strain among domestic and international student sojourners: A longitudinal study. School Psychology International, 23(4), 458-474. 
Hurtado, S. , \& Carter, D. F. (1997). Effects of college transition and perceptions of the campus racial climate on Latino students' sense of belonging. Sociology of Education, 70(4), 324-345.

Hwang, B. J., Bennett, R., \& Beauchemin, J. (2014). International students' utilization of counseling services. College Student Journal, 48(3), 347-354.

Hyun, J., Quinn, B., Madon, T., \& Lustig, S. (2007). Mental health need, awareness, and use of counseling services among international graduate students. Journal of American College Health, 56(2), 109-118.

Institute of International Education (2015). [Inforgraphics of Open Doors Highlights]. A quick look at International students in the U.S. Retrieved from http:/www.iie.org/Research-and-Publications/OpenDoors/Data/Infographics

Jung, E. Hecht, M. L., \& Wadsworth, B. C. (2007). The role of identity in international students' psychological well-being in the United States: A model of depression level, identity gaps, discrimination, and acculturation. International Journal of Intercultural Relations, 31(5), 605-624. doi: 10.1016/j.ijintrel.2007.04.001

Kernahan, C., Wei, Z., \& Davis, T. (2014). A sense of belonging: How student feelings correlate with learning about race. International Journal for the Scholarship of Teaching \& Learning, 8(2), 1-15.

Lee, J. S., Koeske, G. F., \& Sales, E. (2004). Social support buffering of acculturative stress: A study of mental health symptoms among Korean international students. International Journal of Intercultural Relations, 28(5), 399-414.

Levin, S., Van Laar, C., \& Foote, W. (2006). Ethnic segregation and perceived discrimination in college: Mutual influences and effects on social and academic life. Journal of Applied Social Psychology, 36(6), 1471-1501. doi: 10.1111/j.0021-9029.2006.00068.x

Maslow, A. (1962). Toward a psychology of being. Princeton, New Jersey: Van Nostrand Publishing.

Masuda, A., Hayes, S. C., Twohig, M. P., Lillis, J., Fletcher, L. B., \& Gloster, A. T. (2009). Comparing Japanese international college students' and U.S. college students' mental-health-related stigmatizing attitudes. Journal of Multicultural Counseling and Development, 37(3), 178-189.

May, R. (1983). The discovery of being. New York, New York: W. W. Norton \& Company.

Meifen, W., Michael, J. M., Heppner, P. P., Ku, T. Y., Liao, K. Y., \& Wu, T. S. (2007). Acculturative stress, perfectionism, years in the United States, and depression among Chinese international students. Journal of Counseling Psychology, 54(4), 385-394. doi: 10.1037/0022-0167.54.4.385

Misra, R., \& Castillo, L. G. (2004). Academic stress among college students: Comparison of American and international students. International Journal of Stress Management, 11(2), 132-148. doi: 10.1037/1072-5245.11.2.132

Mitchell, S. L., Greenwood, A. K., \& Guglielmi, M. C. (2007). Utilization of counseling services: Comparing international and U.S. college students. Journal of College Counseling, 10(2), 117. 
Mori, S. (2000). Addressing the mental health concerns of international students. Journal of Counseling \& Development, 78(2), 137-144. doi: 10.1002/j.1556-6676.2000.tb02571.x

Munley, P. H., Thiagarajan, M., Carney, S., Preacco, L., \& Lidderdale, M. (2007). Identity and counsellor preference. Counselling Psychology Quarterly, 20(4), 341-360. doi: 10.1080/09515070701690002

O'Keeffe, P. (2013). A sense of belonging: Improving student retention. College Student Journal, 47(4), 605-613.

Poyrazli, S., Kavanaugh, P. R., Baker, A., \& Al-Timimi, N. (2004). Social Support and Demographic Correlates of Acculturative Stress in International Students. Journal of College Counseling, 7(1), 73-82. doi: 10.1002/j.21611882.2004.tb00261.x

Poyrazli, S., \& Lopez, M. D. (2007). An Exploratory study of perceived discrimination and homesickness: A comparison of international students and American students. Journal of Psychology, 141(3), 263-280.

Poyrazli, S. (2015). Psychological symptoms and concerns experienced by international sudents: Outreach implications for counseling centers. Journal of International Students, 5(3), 306-312.

Rahman, O, \& Rollock, D. (2004). Acculturation, competence, and mntal health aong South Asian students in the United States. Journal of Multicultural Counseling \& Development, 32(3), 130-142.

Rajapaksa, S., \& Dundes, L. (2003). 'It's a long way home': International student adjustment to living in the United States. Journal of College Student Retention, 4(1), 15-28.

Shaffer, H. J., Hall, M. N., \& Vander Bilt, J. (2000). Computer addiction: A critical consideration. American Journal of Orthopsychiatry, 70(162-168). doi: 10.1037/h0087741

Schmitt, M. T., Spears, R., \& Branscombe, N. R. (2003). Constructing a minority group identity out of shared rejection: the case of international students. European Journal of Social Psychology, 33(1), 1-12. doi: 10.1002/ejsp.131

Smith, R. A., \& Khawaja, N. G. (2011). A review of the acculturation experiences of international students. International Journal of Intercultural Relations, 35(6), 699-713. doi: http://dx.doi.org/10.1016/j.ijintrel.2011.08.004

Sümer, S., Poyrazli, S., \& Grahame, K. (2008). Predictors of depression and anxiety among international students. Journal of Counseling \& Development, 86, 429-437.

Swagler, M. A., \& Ellis, M. V. (2003). Crossing the distance: Adjustment of Taiwanese graduate students in the United States. Journal of Counseling Psychology, 50(4), 420-437. doi: 10.1037/0022-0167.50.4.420

Taylor, R. (2011). Confucius, the Analects: The Path of the Sage: Selections Annotated \& Explained. (J. Legge, Trans.). Woodstock, Vermont: SkyLight Paths Publishing.

Trice, A. G. (2004). Mixing it up: International graduate students' social interactions with american students. Journal of College Student Development, 45(6-), 671-687.

Trice, A. G. (2007). Faculty perspectives regarding graduate international students' Isolation from host national students. International Education Journal, 8(1), 108-117. 
Tung, W. C. (2011). Acculturative stress and help-seeking behaviors among international students. Home Health Care Management \& Practice, 23(5), 383-385. doi: 10.1177/1084822311405454

Yakunina, E. S., \& Weigold, I. K. (2011). Asian international students' intentions to seek counseling: Integrating cognitive and cultural predictors. Asian American Journal of Psychology, 2(3), 219-224. doi: 10.1037/a0024821

Yakunina, E. S., Weigold, I. K., \& McCarthy, A. S. (2011). Group counseling with international students: Practical, ethical, and cultural considerations. Journal of College Student Psychotherapy, 25, 67-78. doi: 10.1037/00220167.54.4.385

Ye, J. (2005). Acculturative stress and use of the Internet among East Asian international students in the United States. Cyberpsychology \& Behavior: The Impact Of The Internet, Multimedia And Virtual Reality On Behavior And Society, 8(2), 154-161.

Yeh, C. J., \& Inose, M. (2003). International students' reported English fluency, social support satisfaction, and social connectedness as predictors of acculturative stress. Counselling Psychology Quarterly, 16(1), 15.

Ying, Y. W. (2002). Formation of cross-cultural relationships of Taiwanese international students in the United States. Journal of Community Psychology, 30(1), 45-55.

Ying, Y. W., \& Han, M. (2006). The contribution of personality, acculturative stressors, and social affiliation to adjustment: A longitudinal study of Taiwanese students in the United States. International Journal of Intercultural Relations, 30(5), 623-635. doi: http://dx.doi.org/10.1016/j.ijintrel.2006.02.001

JENNIFER T. YOUNG, Psy.D. is currently a psychologist working at United States Peace Corps. This article was written when Dr. Young was working as a psychologist at California State University Long Beach. No part of this manuscript represents the official stance or opinion of the U.S. Peace Corps. Email: dr.jenniferyoung@gmail.com 